\section{Measuring attitude change in medical students: lessons from a short course on global health}

\author{
Adrian Hastings, ' Raúl Pardíñaz-Solís, ${ }^{2}$ \\ Matthew Phillips, ${ }^{3}$ Martina Hennessy ${ }^{3}$ \\ 'Department of Medical and Social Care \\ Education, Leicester Medical School, \\ University of Leicester; '2Skillshare \\ International, Leicester, UK; ${ }^{3}$ Trinity \\ College, Dublin, Republic of Ireland
}

\begin{abstract}
Educators seek to influence attitudes as well as enhance knowledge and skills. We wanted to know how a one week course on global health had altered the attitudes of the learners. We were aware that analysing group responses to Likert items using an interval approach has methodological flaws. All 126 third-year students at Trinity College Medical School were invited to complete an attitude survey before and after the course, with 18 Likert items. Changes in attitudes to each item were analysed by interval and ordinal methods. A total of $82(65 \%)$ students completed both surveys and gave consent. There was a nine-fold difference in attitude change by individual students. Attitudes changed markedly in relation to some items and little to others. Analysing responses using an ordinal method revealed significant change regardless of whether responses to each item before the course were clustered at one end of the scale or were more neutral. The most sensitive and reliable analysis was an ordinal approach, presenting degrees of attitude change by individuals to each item. When presented by the change step method in a histogram important attitude change by individuals within the group is revealed, that the interval method conceals.
\end{abstract}

\section{Introduction}

Trinity College, in Dublin, Ireland has developed an innovative, one-week course with Skillshare International. It aims to develop medical students' understanding of emerging health issues in Ireland and their relationship with global health issues and international development. It is delivered to all students during the second semester of the third year.

The development of instruments that measure attitude and its change is challenging. Attitude has been defined as a predisposition or tendency to respond positively or negatively towards a certain idea, object or situation. ${ }^{1} \mathrm{~A}$ common technique is to present items and ask respondents to express their degree of agreement with these, using a reference scale. ${ }^{2}$ When treating responses as interval data, numerical values are attributed to points on the scale and group mean responses are measured with tests of statistical significance applied to the degrees of change. There are methodological problems with this approach. ${ }^{3}$

The most serious is that important changes within the group can be masked. If at the start of a course all the respondents are neutral towards an item on a five-point scale this will give a group mean response of 2 . If at the end half the respondents strongly agree with the same item and half strongly disagree this will produce an identical group mean. In fact all respondents have changed their attitudes to a considerable degree. A further criticism is that it assumes that each interval is of equal weight but the translation of the concept of level of agreement into a number is at best a crude approximation of the meaning of the response from the individual. ${ }^{3}$

Responses to different items that relate to an overarching concept are often grouped and summated to create a Likert Scale because this will enhance statistical power to detect significant change. ${ }^{4}$ This approach assumes each item contributes equally to the overall concept, that every item has a clear direction of desired response and that the intervals between each response category are of identical difference. This is not an appropriate method of analysis for data concerning attitude change. It would violate the principle that, taken as a whole the survey should minimise the potential distortions of Likert items produced by central tendency, acquiescence and social desirability biases. We sought to avoid these by the choice of a scale without a mid point, by constructing a range of items to produce responses across all four points and by indicating clearly in our instructions that there was no response we hoped to see, either before or after the course.

We describe how a novel approach to analysing responses has given better insight into attitude change. This shows whether individual students change their response and the magnitude of that change. It is a variation of the ordinal approach which regards responses as belonging to a category and usually represents them as numbers or proportions by a bar on a histogram chart.

\section{Innovation}

Eighteen items were written by the faculty for this course, to elicit attitudes towards concepts taught. The learning objectives were each headed by a verb - Describe; Understand; Discuss; Explain; Debate; Explore. This order
Correspondence: Adrian Hastings, Department of Medical and Social Care Education, Leicester Medical School, University of Leicester, UK, LE1 $9 \mathrm{HN}$.

Tel. +44.0116.223.1561 - Fax +44.0116.223.1585. E-mail:amh5@le.ac.uk.

Key words: attitude, medical students, global health.

Conflict of interest: Raúl Pardínaz-Solís was employed by Skillshare International, which is funded by Trinity College Dublin to assist in the development and delivery of the course. The remaining authors report no declarations of interest.

Contributions: AH and RP-S led the conception and design of the evaluation. AH wrote the initial manuscript. All authors contributed to data acquisition and analysis, and the drafting and revision of the manuscript and approved the final version for publication. AH, RPS

Received for publication: 22 September 2011. Accepted for publication: 15 December 2011.

This work is licensed under a Creative Commons Attribution NonCommercial 3.0 License (CC BYNC 3.0).

(C) Copyright A. Hastings et al., 2012

Licensee PAGEPress srl, Italy

Medical Education Development 2012; 2:e1 doi:10.4081/med.2012.e1

demonstrates a sequence moving from an objective that entails acquisition of knowledge to one where the attitudes of the student are central to an appreciation of the impact of the teaching. The inventory was distributed at the start and at the end of the course (an interval of eight days). Items were placed in a random order, with answers recorded on a 4 point Likert scale. Student responses were anonymous as before and after forms were paired using a reference number provided by students, that was unknown to the course leaders. The first form also elicited their consent to use their responses in our evaluation. As the exercise was deemed to be a course evaluation and anonymity protected, ethical approval was not required. The data was analysed and figures in this paper prepared using an Excel spreadsheet.

Of the students on the course 82 completed both surveys and gave consent. Figure 1 shows the degree of agreement or disagreement for all 18 items at the start of the course $(n=95)$. Some items produced very strong agreement, e.g. Item 16. Some elicited a more neutral response, e.g. Item 9 . Others showed disagreement overall, e.g. Item 10.

Table 1 lists each item and presents the results for attitude change by the interval and 
ordinal methods. For the interval approach students' responses were coded by allocating a number for each response from 4 (strongly agree) to 1(strongly disagree); the average response by the whole cohort was calculated before and after the course. Change is represented by the difference in the average before and after the teaching. The larger the number the greater is the shift in attitude in the whole group towards or against the item.

The last column uses a change steps method of presenting an ordinal approach to the analysis and illustrates how this method reveals change in attitudes even when traditional models show or little no overall change. Here the attitude of individual students (before and after) to each item is considered. Figure 2 illustrates different ways (but which could be in either direction) a student's attitude can move.

The ordinal column in Table 1 shows the net number of change steps when those made by students moving in one direction are offset by those in the other.

\section{Evaluation}

The interval method produces averages of the whole group's response. The change steps approach provides a richer insight into how attitudes are changing. We illustrate this by presenting graphs of attitude change to three of the 18 items. Each graph shows the number of students making each of the seven possible changes, the total number of change steps and the overall direction of change within the whole group.

Figure 3 Developing countries subsidise the Irish health services when their doctors come to work here was the item that revealed greatest overall change in attitude by both methods. However the change steps approach shows that 10 students actually moved in the opposite direction to the whole group, 29 students did not change their response, 28 students became more concordant by one step and nine students by two steps.

Figure 4 Educating women is the key to ensuring accessible health care for everyone is an example of an item where the change step'approach reveals more substantial change than implied by the interval method. Although the interval approach ranks this item fourth for degree of change it was the item with the second highest degree of change by the change steps method. Furthermore, it cannot show that seven students bucked the trend and disagreed more after the course.

Figure 5 Private medicine in developing countries has an important role because people value what they pay for was a relatively neutral item at the start of the course with only a small

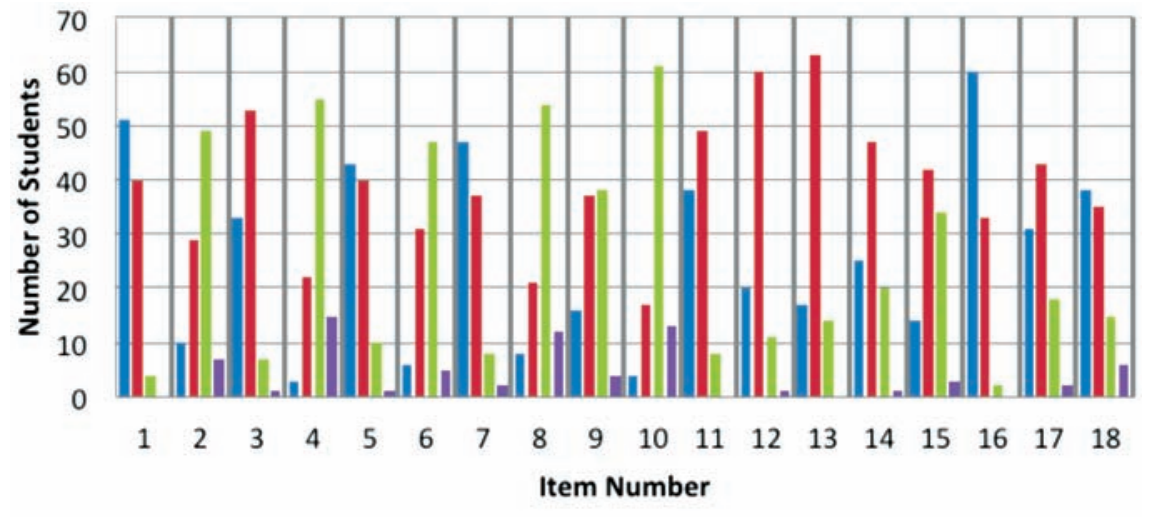

\section{= Strongly agree Agree $=$ Disagree $=$ Strongly disagree}

Figure 1. Degree of agreement with each item at the start of the course $(n=95)$.

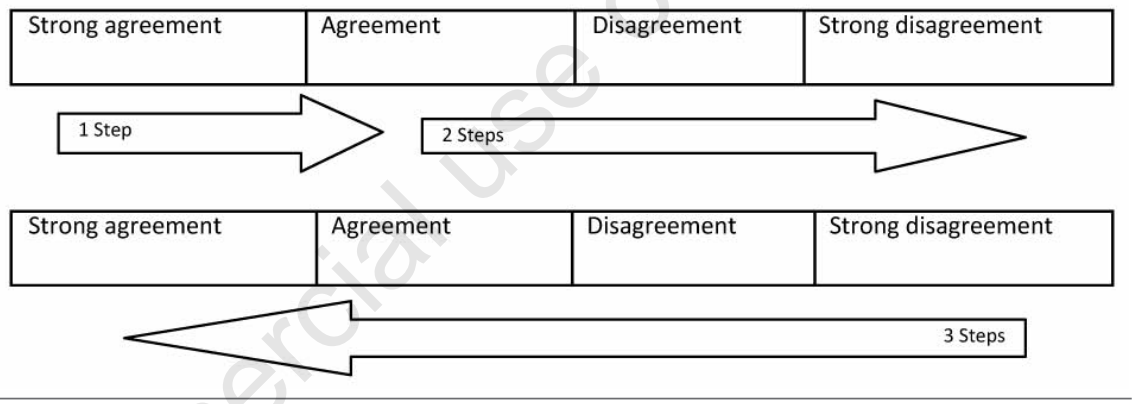

Figure 2. Change Steps. Different ways a student's attitude can move.

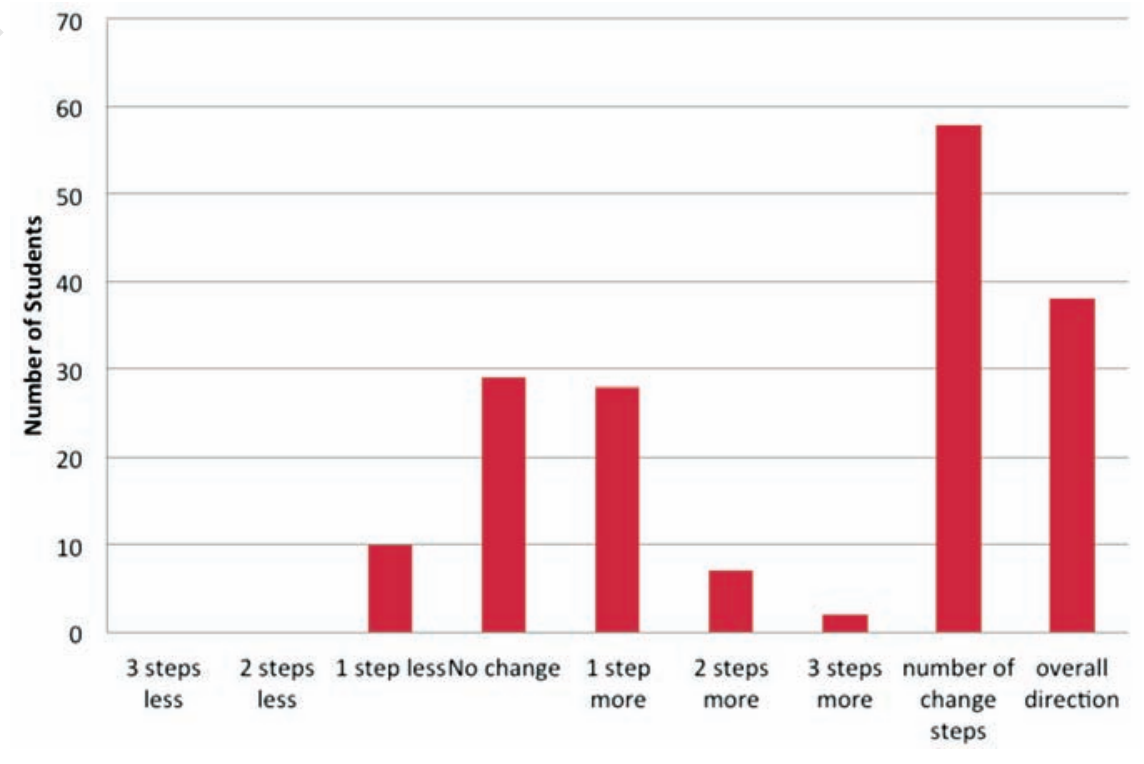

Figure 3. Developing countries subsidise the Irish health services when their doctors come to work here $(n=82)$. 
Table 1. Degrees of attitude change in favour of the statement $(n=82)$.

\begin{tabular}{|c|c|c|c|}
\hline & Attitude Survey Item & $\begin{array}{l}\text { Interval } \\
\text { Change in } \\
\text { agreement } \\
\text { on } 4 \text { point } \\
\text { scale }\end{array}$ & $\begin{array}{l}\text { Ordinal } \\
\text { Change } \\
\text { steps - } \\
\text { overall } \\
\text { direction }\end{array}$ \\
\hline 1 & Helping Communities protect their environment is an important part of health promotion & 0.10 & 11 \\
\hline 2 & Private medicine in developing countries has an important role because people value what they pay for. & -0.06 & -4 \\
\hline 3 & Educating women is the key to ensuring accessible health care for everyone. & 0.21 & 19 \\
\hline 4 & $\begin{array}{l}\text { Experts from developed countries rarely improve health because they do not understand the culture of the poor } \\
\text { countries they work in. }\end{array}$ & 0.08 & 2 \\
\hline 5 & Over-population is a major social factor contributing to poor health in developing countries. & -0.23 & -19 \\
\hline 6 & Developing countries subsidise the Irish health services when their doctors come to work here & 0.45 & 38 \\
\hline 7 & Immunisation against serious communicable disease should be obligatory to protect the whole community. & 0.05 & 2 \\
\hline 8 & People should be able to buy anti-malarial drugs, without consulting a health professional, to improve access to treatment. & -0.12 & -8 \\
\hline 9 & Lack of science education is the main barrier to acceptance of immunisation programmes in developing countries. & 0.27 & 16 \\
\hline 10 & Climate change is the single greatest threat to global health. & 0.19 & 16 \\
\hline 11 & Inequality of income is an important factor producing poor health in all countries of the world. & 0.03 & 6 \\
\hline 12 & Fair trade will enable developing countries to invest in measures to improve health. & -0.03 & 2 \\
\hline 13 & Ireland should expand the training of overseas medical specialists to aid developing countries. & -0.01 & 2 \\
\hline 14 & Investing in vaccine development will be more cost effective than producing new drugs to treat malaria. & 0.08 & 9 \\
\hline 15 & The health care of women in developing countries is neglected because men control political systems. & 0.08 & 6 \\
\hline 16 & Access to health care, free at the time of need is a fundamental human right. & 0.05 & 5 \\
\hline 17 & Developing countries spend too much money on weapons, which would be better spent on health care. & 0.09 & 7 \\
\hline 18 & Political freedom and democratic government are essential to the good provision of health services. & -0.13 & -14 \\
\hline
\end{tabular}

majority in disagreement. The interval method produced five items with a smaller degree of change and the ordinal method four. However, the change step approach adds considerable additional value to the analysis. We can see that although there is little change in overall direction in the whole group $55 \%$ of the students have changed their attitude to this item, 6 of them by two change steps.

\section{Individual degree of attitude change}

Using the ordinal approach it is possible to rank students according to the number of change steps each individual makes over the duration of the course. The range of change steps per student for all items was $2-18$. The median value was 9 with an average of 8.9. Therefore some students displayed stable attitudes; others appear to have been much more influenced by the course.

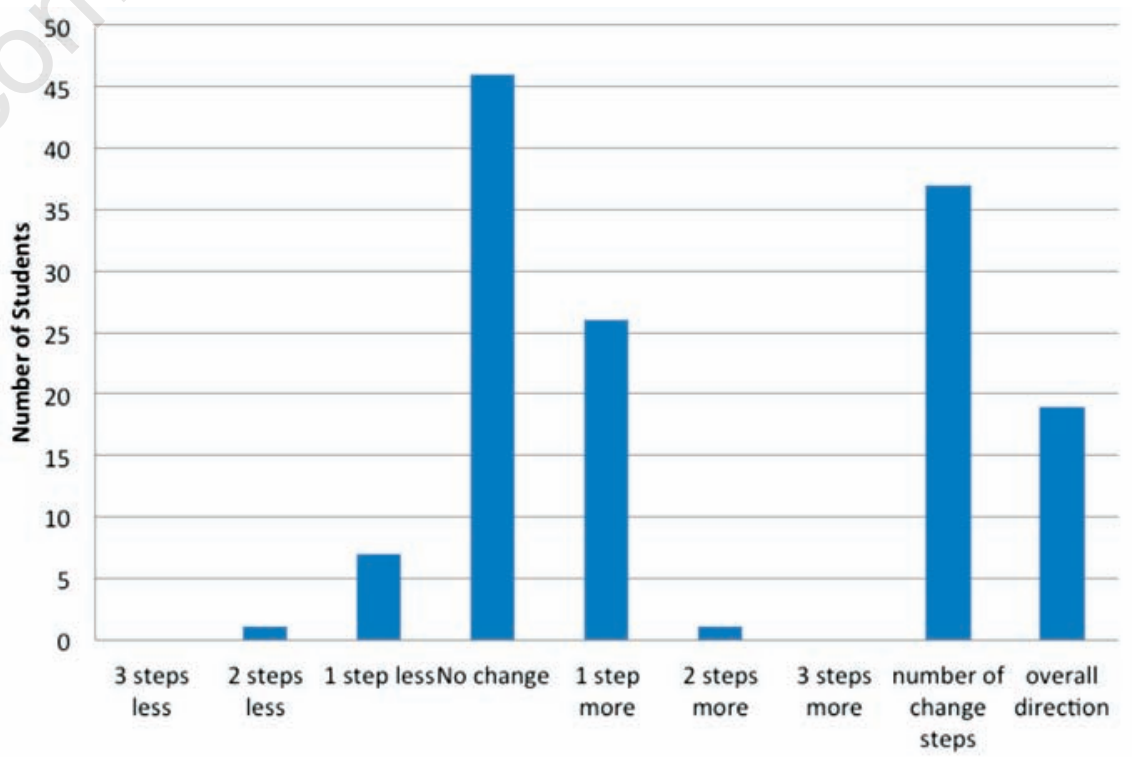

Figure 4. Educating women is the key to ensuring accessible health care for everyone $(\mathbf{n}=82)$. 


\section{Limitations}

Our four available scale points do not produce true interval-level data and therefore our method of analysis using change steps can be criticised because we are assuming each step has equal weight. We believe that the distortion produced does not invalidate our method of analysis and that the advantages more than compensate. If a whole group moved from strong agreement to agreement this would not have the same meaning as going from agreement to disagreement, although it would produce the same number of change steps. However, because each of our student's responses is matched to their own previous reply we reliably report the direction of travel.

\section{Conclusion}

The method we describe allows ranking of students by the degree to which their attitude changes during the course. Course leaders are then able to explore by qualitative methods such as free text questions, focus groups or personal interview the reasons for the differences in apparent impact of the course on individuals.

A further advantage of our method is that significant change in attitudes is clearly revealed even when changes by interval methods are small. The histograms provide much better insight into how attitudes are moving within the group than do single numbers. Although both methods show similar relative magnitude and direction of change in this study, when much smaller numbers of students

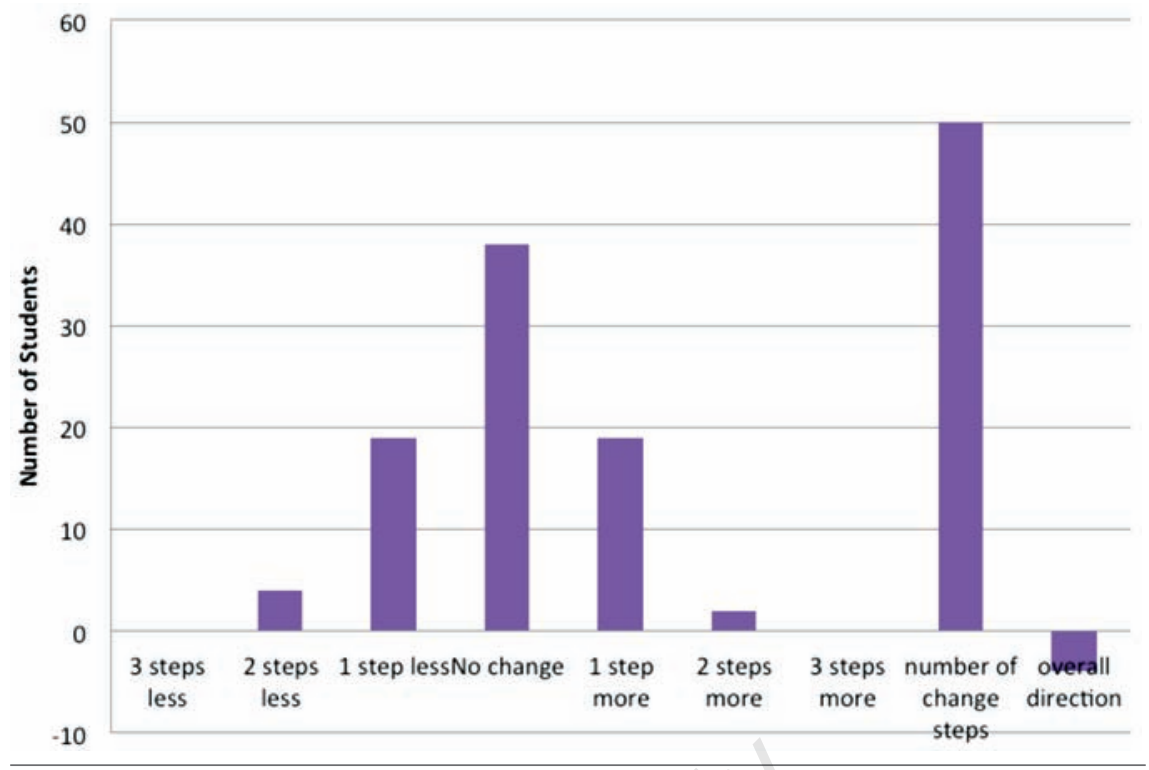

Figure 5. Private medicine in developing countries has an important role because people value what they pay for $(n=82)$.

are being surveyed important attitude change is very likely to be concealed by averages. We believe that the change step approach gives course designers a more precise and useful tool to analyse the impact of courses they are designing when the assessment of attitude change is a required outcome.

\section{References}

1. BusinessDictionary.com. Attitude. Availa- ble from: http://www.businessdictionary. com/definition/attitude.html. Accessed on 23 September 2011.

2. Blue AV, Crandall $S$, Nowacek $G$, et al. Assessment of matriculating medical students knowledge and attitudes towards professionalism. Med Teach 2009;31:92832.

3. Jamieson S. Likert scales: how to (ab)use them. Med Educ 2004;38:1217-8.

4. Carifio J, Perla R. Resolving the 50-year debate around using and misusing Likert scales. Med Educ 2008;42:1150-2. 